\title{
Tumor of follicular infundibulum with unique features
}

\author{
Natalie Haddad ${ }^{1}$ \\ Alexandre Ozores Michalany ${ }^{1}$
}

\author{
Jayme de Oliveira Filho ${ }^{1}$ \\ Kassila da Rosa Nasser ${ }^{1}$
}

\author{
Mariana Junqueira Lacerda Reis ${ }^{1}$ \\ Ana Maria França Corbett ${ }^{1}$
}

\section{DOI: http://dx.doi.org/10.1590/abd1806-4841.20143046}

\begin{abstract}
Tumor of the follicular infundibulum is a rare benign cutaneous adnexal neoplasm with variable clinical presentation. In most cases the diagnosis is made with the help of histopathology, due to lack of a characteristic clinical presentation. The most common form is a solitary lesion, but it can be multiple or eruptive, then called infundibulomatose. This case report illustrates a patient with multiple lesions of tumor of the follicular infundibulum with bizarre aspect and atypical location.
\end{abstract}

Keywords: Neoplasms; Neoplasms, adnexal and skin appendage; Skin abnormalities; Skin diseases; Skin manifestations; Skin neoplasms; Skin and connective tissue diseases

\section{INTRODUCTION}

Tumor of the follicular infundibulum (TFI), also called infundibuloma, was described for the first time in 1961 by Mehregan and Butler. ${ }^{1}$ It is a rare benign cutaneous adnexal neoplasm with varied forms of clinical presentation: 1) solitary; 2) multiple or eruptive; 3) associated with Cowden's disease, nevus sebaceous, Schöpf-Schulz-Passarge syndrome and 4) simultaneously to other cutaneous tumors. ${ }^{2}$ As it does not have a characteristic clinical presentation, in most cases the diagnosis is done with the help of histopathology.

The most common form is the solitary lesion, which begins to affect women at midlife. Its location is the head and neck and the presentation is papulonodular, scaly, asymptomatic, measuring up to $1-2 \mathrm{~cm}$, simulating a basal cell carcinoma. The eruptive/multiple form (infundibulomatose), on the other hand, described by Kossard, is rarer and occurs with multiple lesions on the face, neck and upper trunk, symmetrically, with an aspect of hypopigmented macules or papules, brown or reddish. Sunlight exposure highlights hypopigmented multiple lesions, which remain this way, while the surrounding skin gets tanned. Solitary and multiple variants present a similar microscopic aspect, with proliferation in a fenestrated plaque of pale keratinocytes arranged in anastomosed trabeculae and connected to the epidermis. ${ }^{3}$ The present case illustrates multiple lesions of bizarre aspect.

\section{CASE REPORT}

A 53-year-old male patient presents multiple star-shaped lesions, discreetly atrophic, hypopigmented with light erythema and surrounding hyperchromia, forming a main plaque of $8 \mathrm{~cm}$ on the posterior face of right lower limb and other smaller lesions distributed along the member (Figures 1 and 2). ${ }^{3} \mathrm{He}$ reports that the lesions appeared 38 years ago on the posterior face of the right leg and progressively spread all over the member. He denied any symptoms.

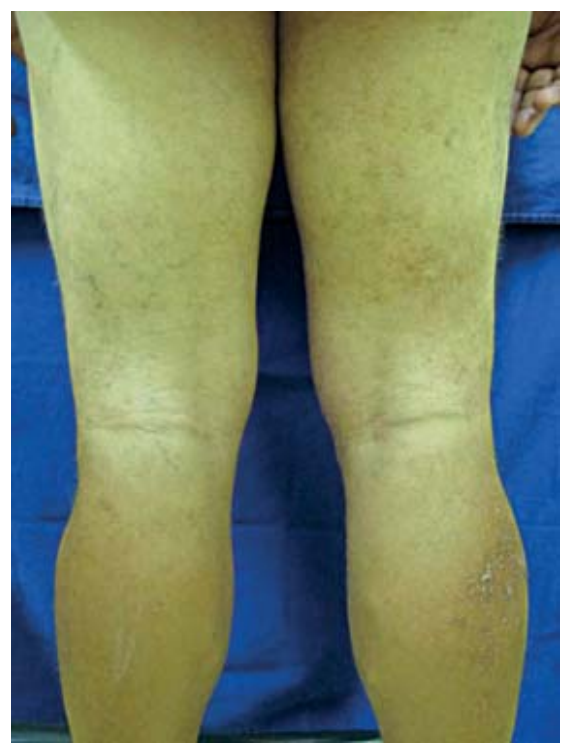

FIGURE 1:

Overview of posterior face of lower limbs

\footnotetext{
Received on 10.08.2013.

Approved by the Advisory Board and accepted for publication on 10.10.2013.

Work performed at Universidade de Santo Amaro (UNISA) - Santo Amaro (SP), Brazil.

Conflict of interest: None

Financial funding: None

Universidade de Santo Amaro (UNISA) - Santo Amaro (SP), Brazil.

(C)2014 by Anais Brasileiros de Dermatologia
} 


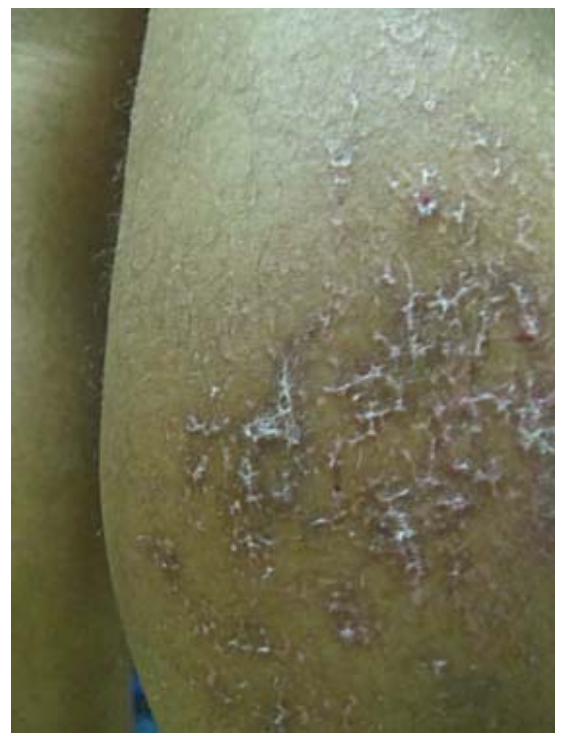

FIGURE 2:

Star-shaped hypochromic lesions with hyperchromia on the edges, located on the posterior face of lower right $\operatorname{limb}$

Two biopsies were done in distinct sites. The microscopic examination evidenced benign epithelial neoplasm, characterized by irregular projections that are formed in the epidermis and are anastomosed with each other in the subjacent dermis, whose cells show clear cytoplasm with normochromatic regular nuclei (Figure 3 and 4). PAS staining was strongly positive in the cytoplasm of these cells (Figure 5). The stroma of neoplasm is fibrillar connective with proliferation of blood capillaries. These findings were consistent with the diagnosis of multiple tumor of follicular infundibulum (infundibulomatosis).

\section{DISCUSSION}

The original report about the tumor of follicular infundibulum was published in 1961 by Mehregan and Butler and described a patient with multiple lesions, like in our case. However, since then, only a few cases of patients with multiple tumors were reported.

It is more frequently found as a solitary lesion, which usually occurs in elderly patients, especially females.

The tumors involve mainly the face, neck and upper trunk. ${ }^{4}$ The clinical aspect is usually a smooth or slightly keratotic papule, which frequently is diagnosed as a seborrheic keratosis or basal-cell carcinoma. Only histological characteristics make the diagnosis possible. ${ }^{2,3}$

Cases of multiple tumors of follicular infundibulum (infundibulomatosis) have been rarely described. They tend to occur in younger patients and present as macules, papules or depressed lesions, which may vary from normochromic to erythematous or hypopigmented. Lesions are usually distributed along the face, neck and upper trunk, differently from

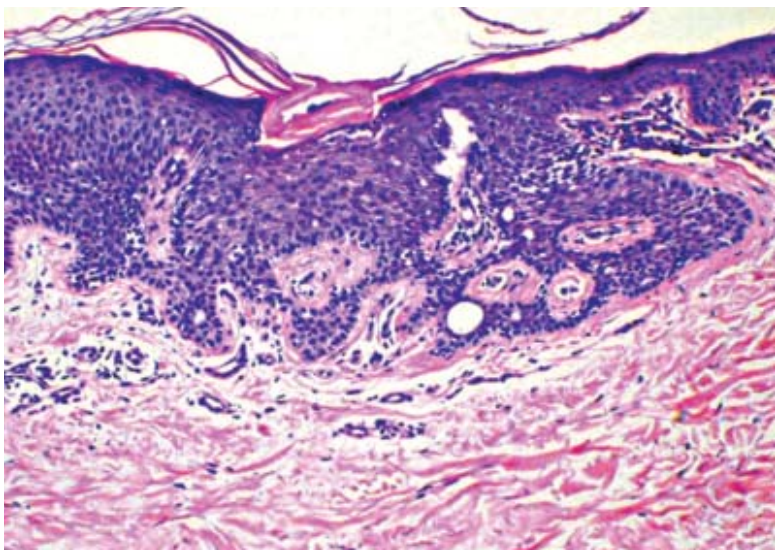

FIGURE 3: Overview of neoplasm constituted of anastomosed epithelial cords, which protrude into the dermis. (HE staining - 100x magnification)

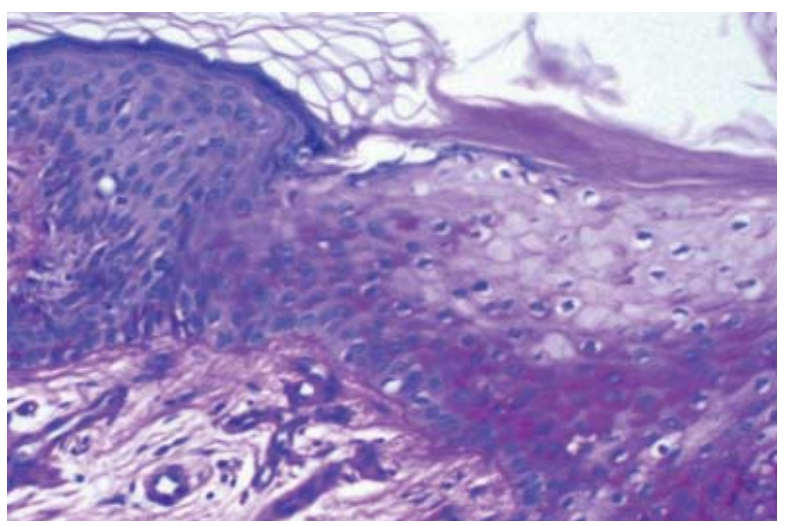

FIGURE 4:Transition area between the lesion and normal epidermis. The cytoplasm of neoplastic cells is larger and clearer than epidermal ones. (HE staining - 200x magnification)

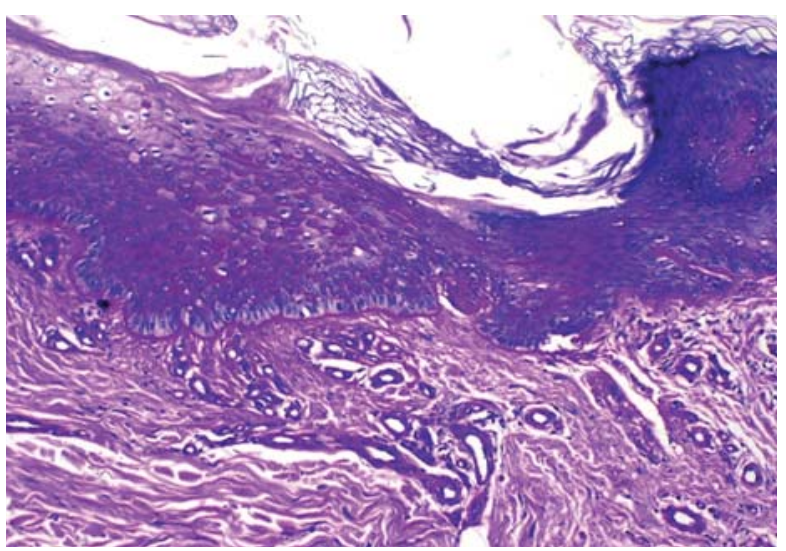

Figure 5:Cytoplasm of cells strongly stained by PAS due to accumulation of glycogen (100x magnification) 
our case. The number of tumors varies from less than 20 to more than a 100. Lesions are prone to be monomorphic in the same patient. ${ }^{5}$

Clinical considerations before achieving a definitive diagnosis may vary according to the characteristic of lesions.

In the few cases described, there is no positive family history and these tumors were not associated with internal malignancy. Nevertheless, it is worth highlighting that tumors of follicular infundibulum may be present in patients with Cowden's syndrome. ${ }^{6}$

Histopathological findings are usually distinct. ${ }^{3}$ In histopathology the tumor is constituted of a proliferation of pale colored keratinocytes in a plaque, in continuity with the epidermis and follicular structures. Cells are monomorphic without atypia, with peripheral palisade of nuclei, which is a common characteristic. ${ }^{3}$ Cytoplasm of tumoral cells is PAS positive, due to the presence of glycogen. One of the main characteristics is the presence of a network of elastic fibers which surround the base of the tumor, which is not present in other benign follicular tumors. ${ }^{1,7}$

Several treatments were described, however all of them with unsatisfactory results.

Tumors of the follicular infundibulum are benign proliferations. However, in a patient with more than 100 lesions, a transformation of two tumors in basal-cell carcinoma was documented. This fact, as well as its occurrence within the spectrum of lesions with appear in Cowden's syndrome, makes the monitoring of these patients advisable.

\section{REFERENCES}

1. Mehregan AH, Butler JD. A tumor of follicular infundibulum. Report of a case. Arch Dermatol. 1961;83:924-7.

2. Sartorelli AC, Leite FE, Friedman IV, Friedman H. Vitiligoid hypopigmented macules and tumor of the follicular infundibulum. An Bras Dermatol. 2009;84:68-70.

3. Kolenik SA 3rd, Bolognia JL, Castiglione FM Jr, Longley BJ. Multiple tumors of the follicular infundibulum. Int J Dermatol. 1996;35:282-4.

4. Findlay GH. Multiple infundibular tumors of the head and neck. $\mathrm{Br} \mathrm{J}$ Dermatol. 1989;120:633-8.

5. Cheng AC, Chang YL, Wu YY, Hu SL, Chuan MT. Multiple tumors of the follicular infundibulum. Dermatol Surg. 2004;30:1246-8.

6. Lee DW, Yang JH, Lee HM, Won CH, Chang S, Lee MW, et al. A Case of Tumor of the Follicular Infundibulum with Sebaceous Differentiation. Ann Dermatol. 2011;23:198-200.

7. Cribier B, Grosshans E. Tumor of the follicular infundibulum: a clinicopathologic study. J Am Acad Dermatol. 1995;33:979-84.

\author{
MAILING ADDRESS: \\ Natalie Haddad \\ Rua Professor Enéas de Siqueira Neto, 340 \\ Jardim das Embuias \\ 04829-300 -São Paulo - SP \\ Brazil \\ E-mail: natahaddad@hotmail.com
}

How to cite this article: Haddad N, Oliveira Filho J, Reis MJL, Michalany AO, Nasser KR, Corbett AMF. Tumor of follicular infundibulum with unique features. An Bras Dermatol. 2014;89(6):964-6. 